\title{
Population genetics of Viviparus (Mollusca: Prosobranchia): homogeneity of $V$. ater and apparent introgression into $V$. contectus
}

\author{
ADAM PORTER* \& GEORG RIBI† \\ Department of Biological Sciences, Bowling Green University, Bowling Green, OH 43403-0212, U.S.A. and \\ $\dagger$ Zoologisches Museum der Universität Zürich-Irchel, Winterthurerstrasse 190, CH-8057 Zürich, Switzerland
}

\begin{abstract}
In Lake Garda at Lazise, Italy, the sympatric snails Viviparus ater and $V$. contectus intermate promiscuously; controlled crosses have previously shown that many $F_{1}$ offspring are viable and fertile and that backcross offspring are viable at least to the age of maturity. Here we report the results of an allozyme study of these taxa documenting introgression. Viviparus ater at Lake Garda is fixed for single alleles at the 10 loci we studied and comparison with $V$. ater populations in Switzerland confirms this genetic homogeneity. We estimate the neighbourhood size of $V$. ater in Lake Garda as $N_{\mathrm{e}} \approx 93400$ using published demographic data; at equilibrium this would support a mean number of 1.37 detectable alleles/locus. $V$. ater is thus not at equilibrium and we suggest it has expanded its range significantly within the last several thousand years. In contrast, $V$. contectus maintains normal levels of genetic variability despite the fact that $V$. ater is more dense than $V$. contectus by a ratio of about $14: 1$. We detected six loci differing between $V$. ater and $V$. contectus and three of these show frequencies consistent with introgression from $V$. ater into $V$. contectus. The levels of introgression we found are consistent with information about the population densities and intermating rates at Lake Garda and with the fitnesses of hybrids bred under controlled conditions. Ultimately, if competitive exclusion does not take place, all the neutral and deleterious alleles in the $V$. contectus population should be replaced by $V$. ater alleles.
\end{abstract}

Keywords: effective population size, enzyme electrophoresis, genetic population structure, interspecific hybridization, introgression, Viviparus.

\section{Introduction}

When introgression between congeneric species is reported in the literature, the species involved usually have parapatric distributions (Barton \& Hewitt, 1985; Arnold, 1992). Such introgression may also occur among species that are sympatric on a large geographical scale (but more or less restricted to different habitat types on a local scale) when organisms have low dispersal rates relative to the scale of habitat heterogeneity. These situations are more common in plants (Nason $e t$ al., 1992) but similar phenomena are reported in some insect hybrid zones (Harrison \& Rand, 1989). In animals, it is rare to find local introgression between broadly sympatric species and, indeed, such cases call the taxonomy into question. Here, we provide genetic

*Correspondence. evidence consistent with local introgression between two sympatric, morphologically and ecologically distinct aquatic snails, Viviparus ater (Cristofori \& Jan) and $V$. contectus (Millet). These taxa have been observed to intermate at significant frequencies in nature (Trüb, 1990; G. Ribi, unpublished data) and they produce fertile $F_{1}$ and backcross progeny under controlled conditions (Trüb, 1990).

Both Viviparus contectus and $V$. ater are large (approximately $3 \mathrm{~cm}$ ), live-bearing, dioecious, freshwater prosobranch snails that feed on benthic detritus and particles suspended in the water column (Cook, 1949). Morphologically, V. ater has shallower depressions between whorls (Fretter \& Graham, 1978) and smooth offspring at birth (Ribi \& Mutzner-Wehrli, 1987); V. contectus has deeper whorls and a row of setae on the newborns' shells. These species also differ in life-history traits (Ribi \& Gebhardt, 1986; Ribi \& 
Mutzner-Wehrli, 1987): $V$. ater has about 20 offspring annually, of 8-12 $\mathrm{mm}$ in shell diameter; $V$. contectus has $40-80$ offspring of 5-8 $\mathrm{mm}$ in size. Finally, $V$. ater has nine chromosomes and $V$. contectus has seven (Fretter \& Graham, 1978). These differences and the sympatric distributions have been deemed sufficient to rank $V$. ater and $V$. contectus as distinct species by taxonomists (Fretter \& Graham, 1978). The taxon $V$. acerosus (Bourguignat) is separated from $V$. ater by very weakly defined characteristics of shell morpho$\operatorname{logy}$. Both $V$. ater and $V$. acerosus are often placed as a subspecies of $V$. viviparus (L.) of northern Europe (Fretter \& Graham, 1978), from which they differ in minor aspects of shell morphology.

Both species occur in shallow water to a depth of 20 $\mathrm{m}$ in lakes and rivers of Europe. Viviparus ater can be found at high densities (more than 10 per $\mathrm{m}^{2}$ ) in the large, low-elevation lakes and rivers of Switzerland and Northern Italy (Trüb, 1990; G. Ribi, unpublished data). $V$. contectus has a more complex distribution, being found sympatrically with Viviparus ater in the lakes of the southern Alps and with $V$. viviparus in Germany and other parts of northern Europe. It is apparently absent from Switzerland north of the Alps. Viviparus contectus seems to prefer shallow, slow-water habitats such as ponds and marshes but also inhabits rivers, canals and large lakes. It is distributed patchily and at low densities $\left(0.05-1\right.$ per $\left.\mathrm{m}^{2}\right)$ when microsympatric in lakes with $V$. ater. Both species mate repeatedly, promiscuously and often interspecifically (Trüb, 1990).

Trüb (1990) peformed a series of reciprocal hybridization experiments lasting several years. He found that viable and fertile $F_{1}$ offspring were produced, although at reduced fecundity and with male-biased sex ratios compared with intraspecific controls. The species of female producing an $F_{1}$ brood had a marked effect on the reduction of fecundity: $V$. contectus females had fecundities reduced to 3 per cent of intraspecific crosses; fecundities of $V$. ater females were reduced to 50 per cent of normal. Reciprocal backcross and $F_{2}$ broods were also produced, with backcrosses yielding low to moderate fecundities. These results demonstrate that a pathway for introgressing alleles exists between these species.

In this paper we ask whether the allozyme frequencies of the two species are consistent with the hypothesis of introgression at Lake Garda, Italy, where the two are found in microsympatry and where interspecific matings are commonly observed. Part of our argument relies on estimation of the effective population sizes of the two species, which we develop in detail in the Discussion. We also report data on genetic differentiation among several populations of $V$. ater in southern Europe.

\section{Materials and methods}

\section{Study populations}

The study populations are given in Table 1 . Snails were gathered and sexed, then maintained in aerated containers of lake water during transport back to the laboratory in Zürich, Switzerland, where they were frozen and maintained at $-80^{\circ} \mathrm{C}$ until electrophoresis in autumn 1991.

\section{Laboratory protocols}

Tissue from the operculum retractor muscle was recovered by removing the operculum and skin of a still-frozen individual. A wedge of tissue was then taken from the retractor muscle, with occasional bits of adjacent tissues. The snails and any remaining tissue were returned to the freezer unthawed and are available for further genetic study. Tissue was homogenized in $200 \mu \mathrm{L}$ of the appropriate gel buffer for the enzyme system stained. We added a small amount of very fine quartz sand $\left(\mathrm{SiO}_{2}\right)$ to facilitate grinding.

We used standard horizontal starch gel electrophoresis throughout at a concentration of $60 \mathrm{~g}$ starch in $500 \mathrm{~mL}$ of gel buffer. We used two gel buffer systems following Ayala et al. (1972): 'JRP' consisted of $1.2 \mathrm{~g}$ Sigma Trizma base, $0.67 \mathrm{~g}$ citric acid and $0.45 \mathrm{~g}$ EDTA per litre; 'Poulik' had $9.3 \mathrm{~g}$ Trizma base and $1.15 \mathrm{~g}$ citric acid per litre. Correspondingly, the JRP bridge buffer contained $16.35 \mathrm{~g}$ Trizma base, $8.25 \mathrm{~g}$ citric acid and $0.46 \mathrm{~g}$ EDTA per litre; the Poulik bridge buffer was $18.2 \mathrm{~g}$ boric acid and $2.4 \mathrm{~g} \mathrm{NaOH}$ per litre. Runs were terminated when a marker dye reached a predetermined location on the gel. Gels were cooled on ice during the run and afterwards for 20-30 min to facilitate handling.

Allelic frequencies, genetic variability scores and deviations from Hardy-Weinberg proportions were calculated using a simple program written (by A.H.P.) for that purpose. We make the standard assumption of referring to electromorphs as alleles; banding patterns of $F_{1} V$. ater-contectus hybrids were consistent with this interpretation.

\section{Results}

The following ten loci produced scorable banding patterns: adenylate kinase $(A K-1$; enzyme commission (E.C.) number 2.7.4.7), glyceraldehyde-3-phosphate dehydrogenase (GAPDH; E.C. 1.2.1.12), glutamicoxaloacetic transaminase (GOT; E.C. 2.6.1.1), malate dehydrogenase (MDH-1; E.C. 1.1.1.37), mannose 
Table 1 Key to study populations showing collection dates

\begin{tabular}{cll}
\hline $\begin{array}{c}\text { Population } \\
\text { number }\end{array}$ & \multicolumn{1}{c}{ Name } & \multicolumn{1}{c}{ Taxon } \\
\hline 1 & Lake Maggiore, Switzerland; September 1991 & ater \\
2 & Richterswil, Lake Zürich, Switzerland; 14 September 1991 & ater \\
3 & Lazise, Lake Garda, Italy; March 1989 & ater \\
4 & Schonau, Danube River, Austria; May 1989 & acerosus \\
5 & Lazise, Lake Garda, Italy; March 1989 & contectus \\
\hline
\end{tabular}

phosphate isomerase (MPI; E.C. 5.3.1.8), 6-phosphogluconate dehydrogenase (6-PGD; E.C. 1.1.1.44), phosphoglucose isomerase (PGI; E.C. 5.3.1.9) and phosphoglucomutase (PGM; E.C. 2.7.5.1); Poulik buffer: esterases (EST-1, EST-2, EST-3; E.C. 3.1.1.1). Due to weak staining, we were unable to interpret consistently patterns of acid phosphatase (E.C. 3.1.3.2), aldolase (E.C. 4.1.2.13), diaphorase (E.C. 1.6.2.2) or superoxide dismutase (E.C. 1.15.1.1) on either buffer system. The peptidases (PEP-1, PEP-2, PEP-3; E.C. 3.4.1.1) stained well using the Poulik system. At $P E P-1$ and $P E P-2$ in all populations, banding patterns indicated possible allelic variability that could not be resolved because of poor separation of the bands; these loci were omitted from further analyses.

Allelic frequencies and sample sizes are shown in Table 2. None of the populations showed any deviation from Hardy-Weinberg proportions although it is well known that such deviations are difficult to detect with samples less than several hundred individuals, especially when frequencies are near 0 or 1 (Ward \& Sing, 1970).

Intrapopulation genetic variability scores are shown in Table 3. The $V$. contectus population shows relatively normal proportions of polymorphic loci and heterozygosity (Nevo, 1977), despite the low population density reported by Trüb (1990). The number of alleles per locus indicates that the $V$. contectus population is likely to be of moderate size.

Viviparus ater shows very low intrapopulation genetic variability, with only GOT in the Lake Maggiore population showing a single private allele, although variability estimates will rise a little when the apparent polymorphism of $P E P-2$ can be scored. Variability among populations is virtually absent in $V$. ater $\left(F_{\mathrm{ST}} \ll 0.001\right)$. This is a consequence of the near fixation of the same alleles within populations. We found no differences between the $V$. ater populations and our sample of $V$. acerosus from Schonau, Austria.

We found six of ten loci scored that show differences between $V$. ater and $V$. contectus. Loci with fixed differences between species are GAPDH, EST-1 and $M D H-1$. In the $V$. contectus population, the loci 6 -
$P G D, P G I$ and $P G M$ each have alleles that are fixed in $V$. ater (Table 2) and in 6-PGD the frequency is high at 50 per cent. We saw no evidence of $V$. contectus alleles appearing at low frequency in $V$. ater in our samples.

\section{Discussion}

There are two main issues concerning the population biology of Viviparus that these data help to illuminate. Firstly, the low genetic diversity of $V$. ater seems surprising, standing in contrast to the large population sizes maintained by this species throughout its range. We suggest below that this is partly due to a recent range expansion by $V$. ater and partly to the moderately-sized neighbourhood areas of these snails. Secondly, the low frequencies of alleles from $V$. contectus that are also found in $V$. ater are consistent with Trüb's (1990) data suggesting introgression. The discussion of these issues is facilitated by the estimation of the effective sizes of the $V$. ater and $V$. contectus populations at Lazise.

\section{Effective population size of $\mathrm{V}$. ater}

In continuously distributed populations, the effective population or 'neighbourhood' size $\left(N_{\mathrm{e}}\right)$ is the number of individuals in the area around which an individual's parents can be considered to have been drawn at random from the population (Wright, 1943). This area, the 'neighbourhood area', determines the geographical scale at which populations can adapt to habitat heterogeneity (Wright, 1943, 1969, 1978) and in combination with mutation and selection rates, determines the rate of evolution. $N_{\mathrm{e}}$ can be estimated from demographic data using $N_{\mathrm{e}}=4 \pi \sigma^{2} d$ (Wright, 1946), where $d$ is population density and $\sigma$ is a dispersal parameter representing the standard deviation of distances between birthplaces of parents and offspring. Porter (unpublished) provides an equation to estimate $\sigma$ in sexually reproducing populations; it incorporates sexspecific movement rates, life-table information and age-specific mating probabilities. 
Table 2 Allelic frequencies for each population

\begin{tabular}{|c|c|c|c|c|c|c|}
\hline & & $\begin{array}{l}\text { Lk. Maggiore } \\
\text { ater }\end{array}$ & $\begin{array}{l}\text { Lk. Zürich } \\
\text { ater }\end{array}$ & $\begin{array}{l}\text { Lake Garda } \\
\quad \text { ater }\end{array}$ & $\begin{array}{c}\text { Danube River } \\
\text { acerosus }\end{array}$ & $\begin{array}{c}\text { Lake Garda } \\
\text { contectus }\end{array}$ \\
\hline \multirow[t]{2}{*}{$A K-1$} & & [24] & [25] & [50] & [35] & {$[50]$} \\
\hline & $A$ & 1.00 & 1.00 & 1.00 & 1.00 & 1.00 \\
\hline \multirow[t]{5}{*}{ EST-1 } & & [23] & [25] & {$[50]$} & [35] & [50] \\
\hline & $A$ & & & & & $0.35(0.007)$ \\
\hline & $B$ & & & & & $0.16(0.006)$ \\
\hline & $C$ & & & & & $0.47(0.008)$ \\
\hline & $D$ & 1.00 & 1.00 & 1.00 & 1.00 & \\
\hline \multirow[t]{2}{*}{ EST-3 } & & [23] & [13] & [50] & [35] & {$[50]$} \\
\hline & $A$ & 1.00 & 1.00 & 1.00 & 1.00 & 1.00 \\
\hline \multirow[t]{3}{*}{ GAPDH } & & [23] & {$[25]$} & [50] & [30] & [45] \\
\hline & $A$ & 1.00 & 1.00 & 1.00 & 1.00 & \\
\hline & $B$ & & & & & 1.00 \\
\hline \multirow[t]{3}{*}{ GOT } & & [23] & {$[25]$} & [25] & {$[30]$} & [26] \\
\hline & $A$ & $0.98(0.005)$ & 1.00 & 1.00 & 1.00 & 1.00 \\
\hline & $B$ & $0.02(0.005)$ & & & & \\
\hline \multirow[t]{3}{*}{$M D H-1$} & & {$[24]$} & {$[25]$} & {$[50]$} & [35] & {$[50]$} \\
\hline & $A$ & 1.00 & 1.00 & 1.00 & 1.00 & \\
\hline & $B$ & & & & & 1.00 \\
\hline \multirow[t]{2}{*}{$M D H-2$} & & [24] & [25] & [50] & [35] & [50] \\
\hline & $A$ & 1.00 & 1.00 & 1.00 & 1.00 & 1.00 \\
\hline \multirow[t]{2}{*}{ 6-PGD } & & [23] & {$[25]$} & [50] & {$[35]$} & [50] \\
\hline & $A$ & & & & & $0.50(0.008)$ \\
\hline \multirow{4}{*}{$P G I$} & $B$ & 1.00 & 1.00 & 1.00 & 1.00 & $0.50(0.008)$ \\
\hline & & [24] & {$[25]$} & {$[50]$} & [35] & [50] \\
\hline & $A$ & & & & & $0.95(0.004)$ \\
\hline & $B$ & 1.00 & 1.00 & 1.00 & 1.00 & $0.05(0.004)$ \\
\hline \multirow[t]{4}{*}{$P G M$} & & [24] & {$[25]$} & {$[50]$} & [35] & {$[50]$} \\
\hline & $A$ & 1.00 & 1.00 & 1.00 & 1.00 & $0.05(0.003)$ \\
\hline & $B$ & & & & & $0.02(0.002)$ \\
\hline & $C$ & & & & & $0.93(0.004)$ \\
\hline
\end{tabular}

Values in parentheses are SE; sample sizes in brackets for each locus.

Table 3 Genetic variability scores for all populations

\begin{tabular}{llcccc}
\hline \multicolumn{1}{c}{ Population } & Taxon & $A$ & $\% \mathrm{P}$ & $H_{\text {obs }}$ & $H_{\exp }$ \\
\hline Lake Maggiore & ater & $1.1(0.01)$ & $11.1(1.1)$ & $0.004(0.000)$ & $0.004(0.000)$ \\
Lake Zürich & ater & 1.0 & 0 & 0 & 0 \\
Lake Garda & ater & 1.0 & 0 & 0 & 0 \\
Danube River & acerosus & 1.0 & 0 & 0 & 0 \\
Lake Garda & contectus & $1.78(0.03)$ & $44.4(1.8)$ & $0.12(0.007)$ & $0.136(0.008)$ \\
\hline
\end{tabular}

$A$ : mean alleles/locus; \%P: per cent of loci polymorphic, there were no differences among criteria; $H_{\text {obs }}$ : observed proportion of heterozygotes; $H_{\text {exp }}$ : proportion of heterozygotes calculated from allele frequencies assuming Hardy-Weinberg proportions.

Variances computed using a jackknife algorithm, dropping loci.

Standard errors in parentheses. 
The necessary ecological data to approximate $N_{\mathrm{e}}$ to within an order of magnitude for $V$. ater are available in the literature. Trüb (1990) estimated population density at Lake Garda as $d=14.2$ ater $/ \mathrm{m}^{2}$ and showed that $V$. ater are only active in the lake for about half the year. Ribi \& Arter (1986) studied movements of marked $V$. ater adults in Lake Zürich, from which we calculate that the daily variance in male displacement (distance and direction) is $\sigma_{\Delta \mathrm{M}}^{2}=2 \mathrm{~m}^{2} \mathrm{day}^{-2}$ and for females it is $\sigma_{\Delta \mathrm{F}}^{2}=0.4 \mathrm{~m}^{2}$ day $^{-2}$. Ribi (1986) provided survivorship and fecundity data for $V$. ater from Lake Zürich. Assuming mating frequency does not change with age in this promiscuous species, we calculate that $\sigma \approx 22.9 \mathrm{~m}$ per generation. That is, a neighbourhood of $V$. ater in Lake Zürich occupies an area of radius $2 \sigma \approx 46 \mathrm{~m}$. These calculations assume that passive dispersal, such as by storms or currents, contributes negligibly to the neighbourhood area and relaxing this assumption reinforces our later conclusions. Assuming dispersal rates and life-table parameters are comparable between Lake Zürich and Lake Garda, we then obtain an approximate effective population size of $N_{\mathrm{e}} \approx 93400$ in Lake Garda. V. ater occurs in comparable densities in the other populations we sampled, so similar conclusions would apply. This is a relatively small area and it implies that isolation by distance should play an important role in producing heterogeneity among populations, even among regions within an area the size of Lake Garda.

\section{Effective population size of $\mathrm{V}$. contectus}

Demographic data are not available for $V$. contectus but with the appropriate assumptions an approximation of $N_{\mathrm{e}}$ can be made from our electrophoretic data. Ewens (1964) provides an equation determining the effective number of alleles per locus from the mutation rate $(\mu)$ and effective population size $\left(N_{\mathrm{e}}\right)$. The primary assumption is that the population has remained at nearly the same effective size long enough that an equilibrium has been reached, such that the rate of new alleles entering the population through mutation (or any other deterministic force, such as immigration) equals the rate of loss via genetic drift. The mean number of alleles per locus in $V$. contectus is $A=1.3$ (ignoring alleles that may have introgressed from $V$. ater). We do not know the mutation rate but we can make a conservatively low estimate of $N_{\mathrm{e}}$ by taking a high mutation rate of $\mu=10^{-5}$. We solved the equation numerically for $N_{\mathrm{e}}$ with the computer program MATHEMATICA (Wolfram, 1989) using $A=1.3$ and $\mu=10^{-5}$ and obtained $N_{\mathrm{e}} \approx 2400$ (if $\mu=10^{-6}$, then $N_{\mathrm{e}} \approx 18340$ ). Immigration can confound this estimate somewhat (effectively increasing 'mutation rate' and decreasing $N_{\mathrm{e}}$ ) but as we have found no other $V$. contectus populations in the vicinity of Lazise, we interpret this as being within an order of magnitude of the actual value.

\section{Genetic variability of $\mathrm{V}$. ater}

The level of genetic variability within $V$. ater populations is lower than expected. A large proportion of the southern half of Lake Garda is shallow (less than $20 \mathrm{~m}$ ) and extends for several square kilometres; $V$. ater is distributed throughout this area. A region of this size could be expected to have accumulated large numbers of neutral and weakly deleterious alleles. The expected effective number of accumulated alleles per locus $\left(A_{\text {exp }}\right)$ can be estimated using Ewens (1964, p. 894). Even assuming a mutation rate for $V$. ater of $\mu=10^{-6}$, which yields a conservatively low estimate of $A_{\text {exp }}$, the Lake Garda $V$. ater population would still support an average number of $A_{\text {exp }}=1.37$ effective alleles per locus. Similar expected numbers would apply to other $V$. ater populations.

The observed range of $1 \leq A \leq 1.1$ among $V$. ater populations (which we can take as a generous estimate of the effective number of alleles per locus) implies that there has not been sufficient time for the mutation/drift equilibrium to be established. Among 10 loci in each of three populations, only one polymorphism was found, whereas 11 two-allele polymorphisms spread among these populations would be necessary to obtain a value of $A=1.37$. Clearly $V$. ater is genetically depauperate for its neighbourhood size. This may be attributed either to smaller $V$. ater populations in the past, maintained relatively consistently at neighbourhood sizes about three orders of magnitude smaller, or to a severe bottleneck as might occur during a colonization event.

In addition to low intrapopulation variation, variability is low among $V$. ater populations. Low interpopulation variability is usually attributed to either high gene flow or severe population bottlenecks in the species' past. The low dispersion rate determined above, combined with the fact that all life stages of these snails are relatively large and vulnerable to desiccation (prohibiting overland transport), suggests that gene flow is negligible at the large geographical scales separating the populations we studied. During Pleistocene glaciations, $V$. ater-like populations would probably have found separate refuges in the Po valley of Italy and (as the weakly differentiated taxon $V$. acerosus) in the Danube River near its mouth. Since the beginning of the Pleistocene, these populations should have had enough time to accumulate significant interpopulation variability, yet little was found. 
Clearly $V$. ater is not in equilibrium with regards to genetic diversity at local or regional scales, so the possibility that $V$. ater has relatively recently been introduced to both the Danube and Po valleys from an unknown source should be considered. 'Recently' in this case would be defined relative to the time needed for new alleles to accumulate via mutation, introgression from $V$. contectus and from donor populations outside the present range. Genetic drift in large populations is extremely slow, so from a genetic perspective, such a 'recent' invasion might have taken place over ten thousand years ago. Even so, it is difficult to envision a mechanism other than human-facilitated transport that would accomplish a relatively rapid range expansion of these sedentary organisms over a geographical area the size of southern Europe. This interpretation problem also arises on a smaller geographical scale: Ribi (1986) reviewed evidence suggesting that the Lake Zürich $V$. ater population originated from snails released in the early 1900 s and the subsequent rapid spread of the population throughout the lake could not be explained by the movement rates of the snails alone.

\section{Introgression from $\mathrm{V}$. ater into $\mathrm{V}$. contectus}

Introgression is difficult to demonstrate conclusively because it is not usually possible to separate introgressed alleles from shared alleles inherited from a common ancestor. The introgression argument is only feasible when there are independent, supporting data documenting natural hybridization and documenting the fitnesses of $F_{1} s$ and backcrosses. However, once such supporting evidence is established, the alternative argument for a phylogenetic history of shared alleles seems considerably less parsimonious. Two results indicate that some level of introgression in the field is quite likely. Trüb (1990) documented a high incidence of intermating between $V$. contectus and $V$. ater at Lake Garda and his reciprocal $F_{1}, F_{2}$, and backcross experiments document a biologically significant proportion of viable and fertile offspring. These results imply a relatively low introgression rate (see below) but not so low as to be undetectable using allozyme data.

There are models available to estimate gene flow rates between taxa but the Viviparus system fails to meet the necessary statistical assumptions. Porter's (1990) method of analysing a series of populations of $V$. ater and $V$. contectus in sympatry, using hierarchical F-statistics to estimate the rate of gene flow between them, proved impractical because of the population density difference between $V$. contectus and $V$. ater. It was also impossible to use diffusion equations proposed by Kimura (1964) because the time since $V$. ater and $V$. contectus came into secondary contact is unknown. We rely on a qualitative argument instead.
Given the interspecific population density differences at Lake Garda, introgression into $V$. contectus is much easier to detect than introgression into $V$. ater. If one presumes a 14.2:1 ater:contectus ratio (Trüb, 1990) and one generation of random mating, Hardy-Weinberg proportions indicate that $F_{1}$ hybrids would comprise 96 per cent of all individuals with $V$. contectus genes; the remaining 4 per cent would be pure $V$. contectus. After several generations of hybridization, even including strong selection against hybrids, a relatively small $V$. contectus sample would be sufficient to obtain introgressing alleles flowing from $V$. ater into $V$. contectus. For example, from data on the Lazise populations (Trüb, 1990), backcross offspring were similar enough to be phenotypically indistinguishable from 'pure' $V$. contectus, $\mathrm{F}_{1}$ fecundities were only 3 per cent of fecundities of pure crosses, and backcross fecundities (to $V$. contectus) were of the order of 10-30 per cent of intraspecific fecundities. After only two generations of crossing, these values indicate that 72 per cent of the 'contectus' in the lake would be derived from hybrid ancestry. These introgressed $V$. ater alleles would exist at a mean frequency of 18 per cent and they would increase gradually after further generations of hybridization; introgressed alleles could be quantified quite easily in a sample of $50 \mathrm{~V}$. contectus individuals. Trüb's (1990) data suggest other factors that would reduce the chances of detection in a sample of 50 but these calculations qualitatively guide our expectations of the consequences of introgression. On the other hand, under the same ratio of densities, $10^{3}$ to $10^{4} \mathrm{~V}$. ater individuals would be required to sample appreciable numbers of introgressed $V$. contectus alleles.

In our $V$. contectus sample, the frequencies of $V$. ater alleles we found were 5 per cent, 5 per cent and 50 per cent (Table 2) and there were an additional three loci where no $V$. ater alleles were found. This yields a mean frequency of 10 per cent introgressed $V$. ater alleles and implies lower levels of introgression than expected from the calculations above. We hypothesize several reasons for this discrepancy, not mutually exclusive. Firstly, our calculations above do not account for the strongly male-biased sex ratio of $F_{1}$ hybrids (Trüb, 1990) which would tend to pull the expected introgression rate down somewhat. Secondly, there are different chromosome numbers between $V$. ater and $V$. contectus and differences in pairing ability during meiosis should produce different introgression rates on different chromosomes; our calculations provide expected introgression rates of alleles on the more structurally similar chromosomes. Thirdly, the promiscuous mating system of Viviparus provides opportunity for severe sperm competition and we know nothing about the relative competitive abilities of conspecific and hybrid 
sperm. Finally, there is weak positive assortative mating between $V$. ater and $V$. contectus (Trüb, 1990; G. Ribi \& A. Porter, unpublished data) which will slightly reduce the expected introgression rate. Nevertheless, we predict that $V$. ater alleles of our 'fixed' $V$. contectus loci (EST-1, MDH-1, GAPDH) will be found in $V$. contectus on further sampling.

The Viviparus system in Lake Garda is well suited for the study of swamping effects of introgression under field conditions. It may be possible to estimate the introgression rate by following allele frequencies and population densities in $V$. contectus over the next several generations. If competitive exclusion does not take place, then all the neutral $V$. contectus alleles will ultimately be swamped and replaced by $V$. ater alleles. Furthermore, any adaptive traits of $V$. ater or $V$. contectus, whether quantitatively controlled or based on a single locus, can be expected to spread into the opposite species.

\section{Acknowledgements}

The authors were supported by grant 31-25310.88 from the Swiss National Science Foundation to G.R. and by the Zoologisches Museum. We thank R. Staub and M. Maag for assistance during collecting; H. Hotz and P. Beerli for advice during electrophoresis; $\mathrm{H}$. Burla, $H$. Trüb and P. Ward for useful discussions; and M. Gromko for comments on an earlier draft of the manuscript.

\section{References}

ARNOLD, M. L. 1992. Natural hybridization as an evolutionary process. Ann. Rev. Ecol. Syst., 23, 237-261.

AYALA, F. J., POWELL, J. R., TRACEY, M. L., MOURAO, C. A. AND PEREZSALAs, s. 1972. Enzyme variability in the Drosophila willistoni group. IV. Genetic variation in natural populations of Drosophila willistoni. Genetics, 70, 113-139.

BARTON, N. H. AND HEWITT, G. M. 1985. Analysis of hybrid zones. Ann. Rev. Ecol. Syst., 16, 113-148.

COOK, P. M. 1949. A ciliary feeding mechanism in Viviparus viviparus. Proc. Malac. Soc., 27, 265-271.

EWENS, w. J. 1964. The maintenance of alleles by mutation. Genetics, 50, 891-898.
FRETTER, V. AND GRAHAM, A. 1978. British Prosobranch Molluscs. Their Functional Anatomy and Ecology. Ray Society, London.

HARRISON, R. G. AND RAND, D. M. 1989. Mosaic hybrid zones and the nature of species boundaries. In: Otte, D. and Endler, J. A. (eds) Speciation and its Consequences, pp. 111-133. Sinauer Associates, Sunderland, MA.

KIMURA, M. 1964. Diffusion models in population genetics. $J$. Appl. Prob., 1, 177-232.

NASON, J, D., ELLSTRAND, N. C. AND ARNOLD, M. L. 1992. Patterns of hybridization and introgression in populations of oaks, manzanitas and irises. Am.J. Bot., 79, 101-111.

NEvo, E. 1977. Genetic variation in natural populations: pattern and theory. Theor. Pop. Biol., 13, 121-177.

PORTER, A. H. 1990. Testing nominal species boundaries using gene flow statistics: the taxonomy of two hybridizing admiral butterflies (Limenitis: Nymphalidae). Syst. Zool., 39, 131-147.

RIBI, G. 1986. Within-lake dispersal of the prosobranch snails, Viviparus ater and Potamopyrgus jenkinsi. Oecologia, 69, 60-63.

RIBI, G. AND ARTER, H. 1986. Sex related difference of movement speed in the freshwater snail Viviparus ater. J. Moll. Stud., 52, 91-96.

RIBI, G. AND GEBHARDT, M. 1986. Age specific fecundity and size of offspring in the prosobranch snail, Viviparus ater. Oecologia, 71, 18-24.

RIBI, G. AND MUTZNER-WEHRLI, R. 1987. Is there selection against small offspring of Viviparus ater (Gastropoda, Prosobranchia)? Schweiz. Z. Hydrol., 49, 85-92.

TR̈B, H. R. 1990. Züchtung von Hybriden zwischen Viviparus ater und V. contectus (Mollusca, Prosobranchia) im Zürichsee und ökologische Untersuchungen in einer gemischten Population im Gardasee. Ph.D. Thesis, University of Zürich.

WARD, R. H. AND SING. C. F. 1970. A consideration of the power of the $\chi^{2}$ test to detect inbreeding effects in natural populations. Am. Nat., 104, 355-363.

wolfram, s. 1991. Mathematica, Addison-Wesley, Redwood City, CA.

WRigHT, s. 1931. Evolution in Mendelian populations. Genetics, 16, 97-159.

WRIGHT, s. 1943. Isolation by distance. Genetics, 28, 114-138.

WRIGHT, s. 1946. Isolation by distance under diverse systems of mating. Genetics, 31, 39-59.

WRIGHT, s. 1969. Evolution and the Genetics of Populations, vol. 2. The Theory of Gene Frequencies. University of Chicago Press, Chicago.

WRIGHT, s. 1978. Evolution and the Genetics of Populations, vol. 4. Variability Within and Among Natural Populations. University of Chicago Press, Chicago. 